\title{
Highly sensitive frequency selective surface for structural health monitoring system
}

\author{
S. A. Suhaimi, S. N. Azemi, P. J. Soh, C.B.M.Rashidi, A Abdullah Al-Hadi \\ Advanced Communication Engineering Center (ACE), School of Computer and Communication Engineering, \\ University Malaysia Perlis, Malaysia
}

\begin{tabular}{|c|c|}
\hline Article Info & ABSTRACT \\
\hline Article history: & $\begin{array}{l}\text { This paper is introduced a passive sensor to detect the performance of the } \\
\text { structure using three-dimensional (3D) Frequency Selective Surfaces (FSS) }\end{array}$ \\
\hline Received Sep 25, 2018 & The proposed 3D Circular FSS results are proved behave as passive sensor \\
\hline Revised Nov 26, 2018 & with changing of sensitivity incident angles to be apply in Structural Health \\
\hline Accepted Jan 28, 2019 & $\begin{array}{l}\text { Monitoring (SHM) system. Moreover, this 3D Circular FSS capable to } \\
\text { operate without stand to any (DC/AC) power and very low cost in term of }\end{array}$ \\
\hline
\end{tabular}

Keywords:

3D FSS

Building damage detection

Frequency selective surface

Incident angle

Sensor technology

Structural health monitoring

Copyright $(0) 2019$ Institute of Advanced Engineering and Science. All rights reserved.

\section{Corresponding Author:}

Saidatul Norlyana Azemi,

Advanced Communication Engineering Center (ACE),

School of Computer and Communication Engineering,

University Malaysia Perlis, Malaysia.

Email: snorlyana@unimap.edu.my

\section{INTRODUCTION}

Following the tragic earthquake in Sabah, there are concerns that the earthquake could also hit others place such as national capital and most residents global city of Malaysia which is Kuala Lumpur. According to a geologist, Kuala Lumpur is located near the centers of the ancient fault line zone and most of our buildings are unfortunately not designed for it. Therefore, structural health monitoring (SHM) technologies for civil structures are becoming important. It is used to monitor structural changes such as tension and stress [1-3].

Structural Health Monitoring (SHM) is defined as an integrated procedure for the detection and characterization of damage to the structure or building. The systems are installed on bridges, building and highways in order to improve the capacity of damage detection. Over the past decade, the field of Structural Health Monitoring (SHM) has begun to attract the interest of researchers [4].

Nowadays, SHM system has been offered a huge beneficial for building structure safety and performance. By developing SHM system, it is proved that the percentage of safety increased. SHM is commonly applied to tracking and detect any poor structure performance such as tilting, crack and movement of structure with using various sensors [5-7]. There are many type of sensors have been proposed and applied in SHM system which are wired and wireless sensors. Besides that, mostly researchers are more concentrating to wireless sensor compared to wired sensor due to their higher active element needed and difficulties in installation [8-10].Characteristic of passive sensor has been overcome the active sensor problem in term of easier installation and maintenance, less power consumption and long term of endurance element [11-12]. 
Although there are a lot of works and researches that has been done in wireless sensors and their application in structural health monitoring, all these technologies still have room for improvement. These disadvantages include all these systems require a battery which has a restricted life time, require sensors which are independent from each other and also require antenna that increases the complexity, size of the sensor unit, and weight. It is also costly because they require special skills to fabricate the sensor, and finally require for a wireless sensor network which need complex software and data acquisition units (DAQ). Mostly, all the methods mentioned above is a wired sensors. These sensors have many disadvantages such as the need for installation during building. Wires also limit the structures' functionality, add more complexity to it and increase the heaviness of the structure. Therefore, a new design of technologies is becoming necessary for civil structural health monitoring (SHM)

Regarding to SHM system, wireless sensors for Structural Health Monitoring (SHM) are an emerging new technology that promises to overcome many disadvantages pertinent to conventional, wired sensors. Active wireless sensors network is one of the methods where it is used a combination system of RF communication module, microprocessor, sensing module and battery. It can broadcast the sensing signal up to 100 meter range hence give early indicator for society. Moreover, passive sensors have been developed for tracking abnormalities building structure without pertinent to power supply on itself.

\section{3D FREQUENCY SELECTIVE SURFACES FOR SHM DEVELOPMENT}

The 3D Frequency Selective Surfaces with circular shaped was introduced here to act as a passive sensor. A good performance in term of sensitivity angular response for this circular shaped was chosen [13-14]. A new technique of 3D FSS was proposed in this paper to tracking abnormalities structure performance for SHM system. The electromagnetic wave characteristic will varies by changing the angle of FSS due to the building tilting as shown in Figure 1 (b). The changing (frequency shifting) of different electromagnetic wave characteristics were presenting in two polarizations which is TE- and TM- incident angle. For this case, the TE- and TM- incident angle required to obtain in two different characteristic frequency responses TE and TM angle such sensitive and insensitive angular response respectively. See Figure 1 (c), sensitivity of angular response indicating that the frequency response (band stop) shifting from $3.8 \mathrm{GHz}$ to $3.86 \mathrm{GHz}$ with the angle $0^{\circ}$ to $20^{\circ}$ respectively. Meanwhile, insensitive frequency response (band stop) is maintained in one location of frequency response with various angles up to 60 degrees. Therefore, the building tilting is monitored by a different of sensitivity angular response changing.

The 3D Circular FSS design is shown in Figure 1(c), where behaves as a passive sensor and attached on the building structure. See Figure 2, by increasing the conducting element will render the frequency characteristic. The geometry FSS play an important role towards the frequency behavior [15]. Therefore the frequency response of FSS can be control in two different polarizations by alter the geometry size.

The FSS shape was designed in circular geometry. FSS structure was modified by elevating the height of conducting element. Besides that, 3D Circular FSS has shown the different S21 band stop results in two polarization TE and TM incident angle. Controllable FSS performance and characteristic made the two polarization results become sensitive and insensitive in various angle. Simulation on 3D FSS has been done from $0^{\circ}$ up to $60^{\circ}$.

The dependence of the frequency selective surfaces response on the element height is studied as shown in Figure 2. Based on the results, shows a significant improvement in term of stability angles after increasing the height of elements 3D square FSS. See Figure 3 to 5, the height of the 3D square FSS was optimized from $10 \mathrm{~mm}$ to $25 \mathrm{~mm}$ while keeping its side length and unit cell size constant. TM-incident polarized becomes more stable while TE-incident polarized becomes sensitive toward incident angle as the height increasing. An increase of the element height causes a shift to higher resonant frequencies of the transmission stop band. In Figure 6 indicate that two different polarization TE-and TM- incident angle have been simulated. Result in Figure 2 (b) looks sensitive in various angles and will be used for monitoring in SHM system. Table 1 and Table 2 indicated the percentage different center frequencies in each angle as the FSS (building) changed.

Table 1. Values Center Frequencies of the 3D Circular FSS with Different Angle at TE Incident Angle

\begin{tabular}{ccc}
\hline Degree $\left({ }^{\circ}\right)$ & Frequency $(\mathrm{GHz})$ & Deviation $(\%)$ \\
\hline 0 & 3.81 & 0 \\
20 & 3.816 & 0.15 \\
40 & 3.816 & 0.15 \\
60 & 3.815 & 0.13 \\
\hline
\end{tabular}

Table 2. Values Center Frequencies of the 3D Circular FSS with Different Angle at TM Incident Angle

\begin{tabular}{ccc}
\hline Degree $\left({ }^{\circ}\right)$ & Frequency $(\mathrm{GHz})$ & Deviation $(\%)$ \\
\hline 0 & 3.81 & 0 \\
20 & 3.893 & 2.17 \\
40 & 4.12 & 8.13 \\
60 & 4.38 & 14.9 \\
\hline
\end{tabular}



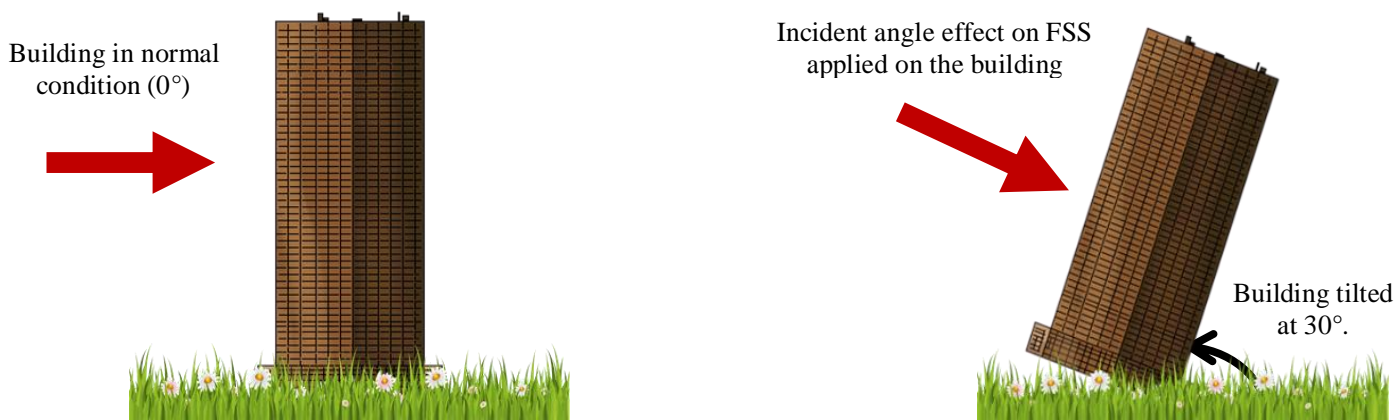

(a)

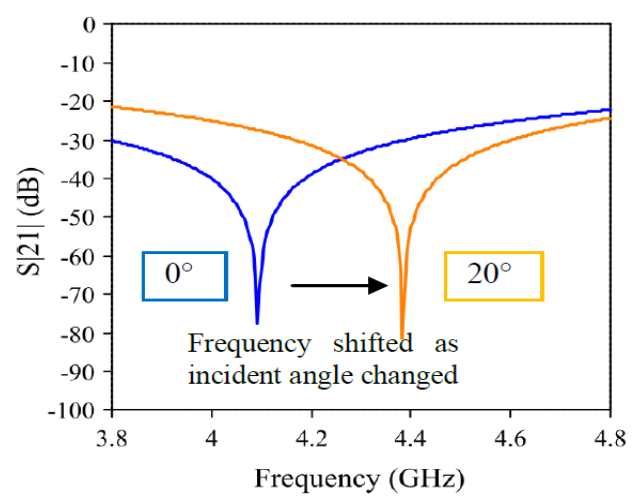

(b)

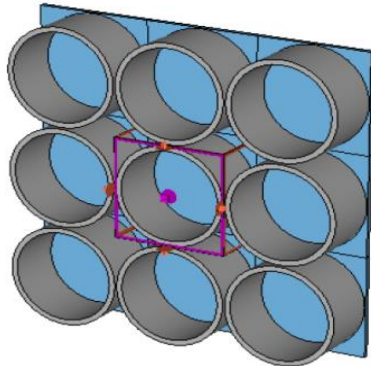

(c)

Figure 1. (a) Incident angle effect as building tilting (b) Frequency response shifting as incident angle changed (from $0^{\circ}$ to $20^{\circ}$ ) (c) 3D Circular FSS design with unit cells

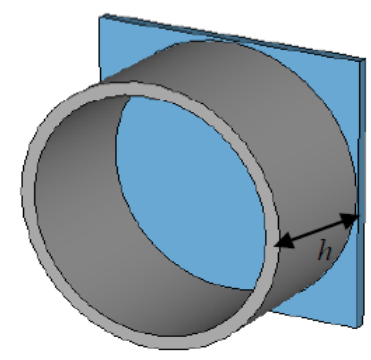

Figure 2. Elevating the height of conducting element

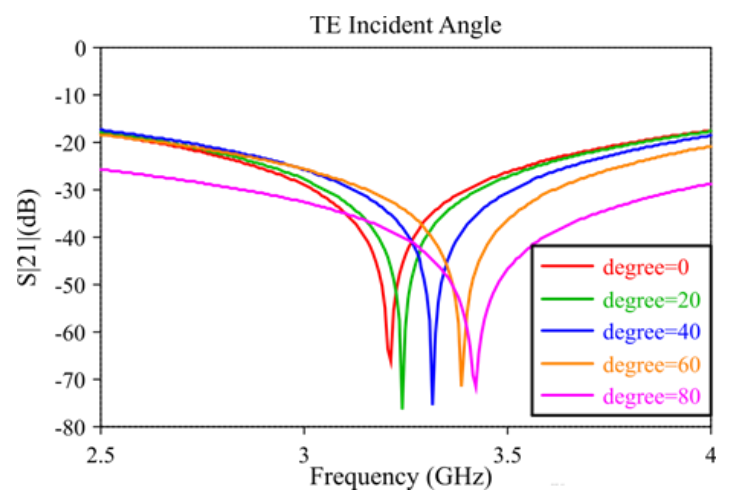

(a)

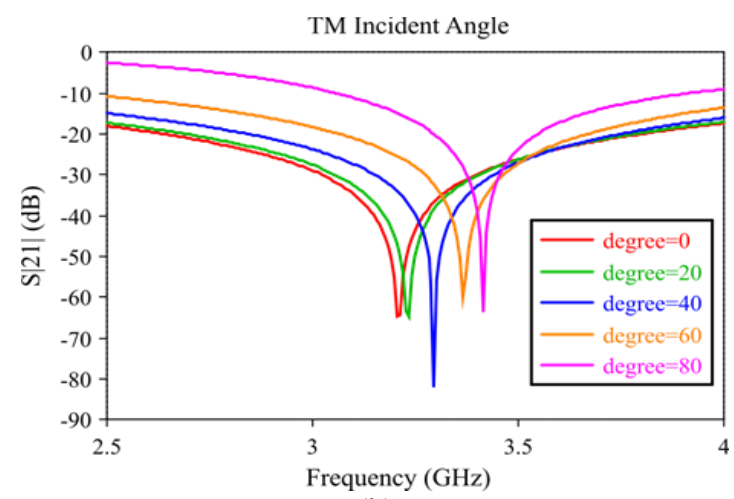

(b)

Figure 3. TE- and TM-polarized incidence at a height of $10 \mathrm{~mm}$ 


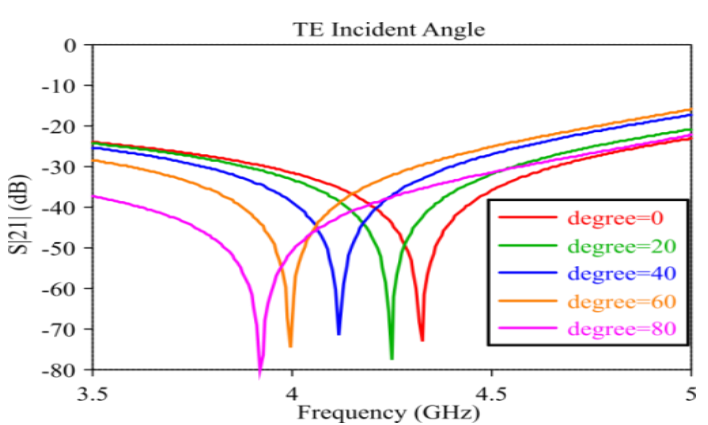

(a)

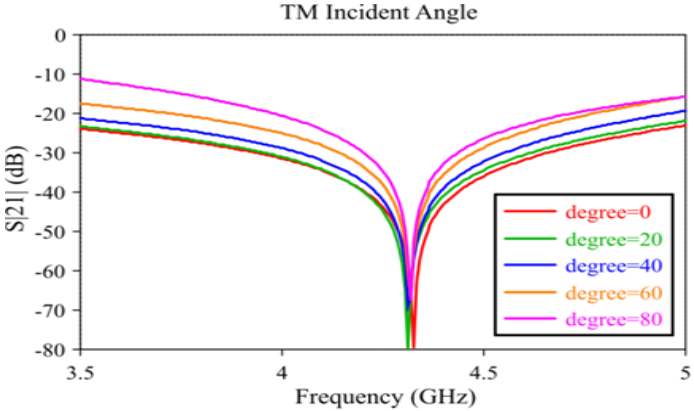

(b)

Figure 4. TE- and TM-polarized incidence at a height of $18 \mathrm{~mm}$

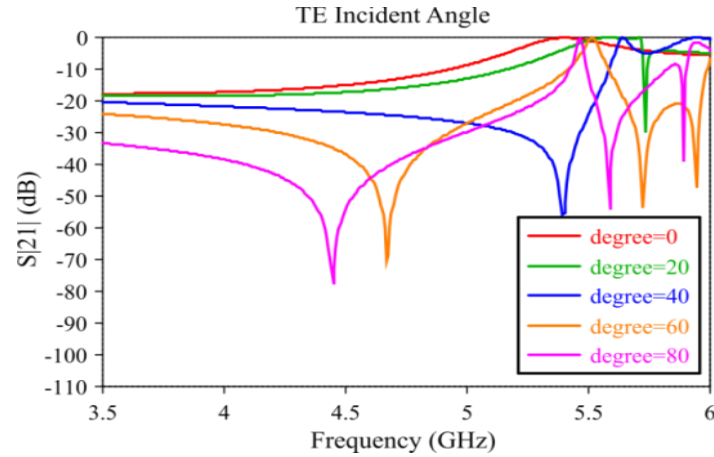

(a)

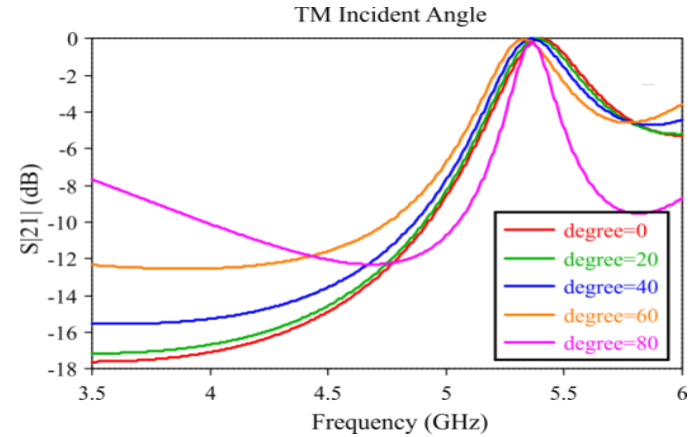

(b)

Figure 5. TE- and TM-polarized incidence at a height of $25 \mathrm{~mm}$

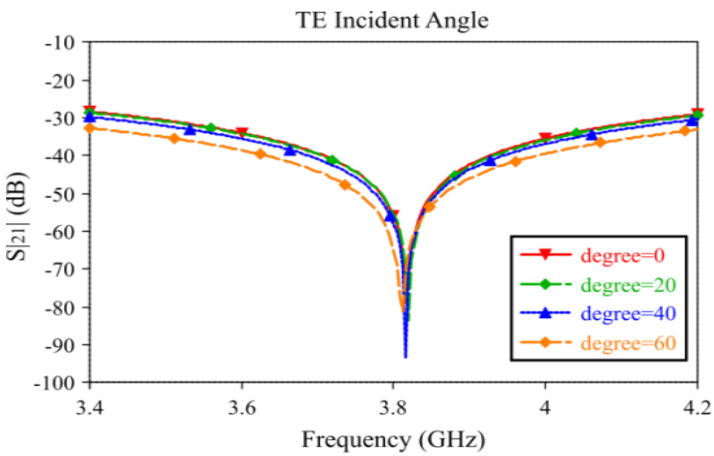

(a)

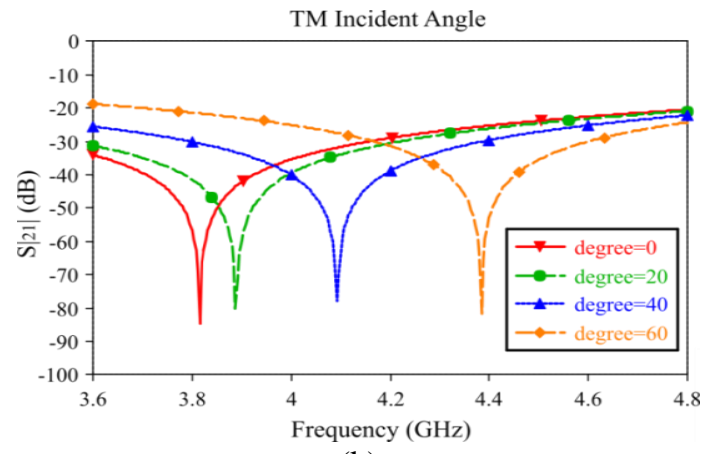

(b)

Figure 6. Frequency response results up to $60^{\circ}$ (a) TE incident angle, insensitive

(b) TM incident angle, sensitive

By changing the height of the unit elements to $10 \mathrm{~mm}, 18 \mathrm{~mm}$, and $25 \mathrm{~mm}$, the center of the bandstop (at 0 degree) shifted to $3.2 \mathrm{GHz}, 4.3 \mathrm{GHz}$, and $5.3 \mathrm{GHz}$ respectively. Significant rate of change can be observed in resonance upon incident angle variations and upon the height increment of the FSS conducting elements. This behavior indicates that the height of the conductor elements influenced the characteristic of the 3D FSS.

\section{CONCLUSION}

The proposed of 3D Circular FSS was introduced to perform as a passive sensor in SHM system. 3D Circular FSS able to utilize without depends on the power supply on it. Moreover, various angles S21 
results shown a sensitivity incident angle (TM-polarized), meanwhile insensitivity (stable) incident angle at TE-polarized. 3D Circular FSS proved that can controlled the sensitivity incident angle in both polarizations instead of 2D FSS structure. A result in Figure 2 (b) has shown a terrific sensitivities frequency shifting as the incident angle of building changed. Therefore, a result will be used as monitoring building performance due to sensitive on different building condition

\section{ACKNOWLEDGEMENTS}

The authors gratefully acknowledge use of the services and facilities of the Advanced Communication Engineering Centre (ACE) CoE, School of Computer and Communication Engineering, Universiti Malaysia Perlis (UniMAP). This project also been funded by Fundamental Research Grant Scheme (FRGS) 9003-00545

\section{REFERENCES}

[1] Brema, J., J. Santhosh Kumar, K. Prathibaa, and T. S. Rahul. "Vibration Measurement of a Steel Bridge Using Smart Sensors: Deployment and Evaluation." In Proceedings of International Conference on Remote Sensing for Disaster Management, pp. 483-491. Springer, Cham, 2019.

[2] Zinno, Raffaele, Serena Artese, Gabriele Clausi, Floriana Magarò, Sebastiano Meduri, Angela Miceli, and Assunta Venneri. "Structural Health Monitoring (SHM)." In The Internet of Things for Smart Urban Ecosystems, pp. 225249. Springer, Cham, 2019.

[3] Martins, A. T., Aboura, Z., Harizi, W., Laksimi, A., \& Hamdi, K. "Structural health monitoring by the piezoresistive response of tufted reinforcements in sandwich composite panels". Composite Structures, 210, 109$117,2019$.

[4] Farrar, Charles R., and Keith Worden. "An introduction to structural health monitoring." Philosophical Transactions of the Royal Society A: Mathematical, Physical and Engineering Sciences 365.1851, 303-315, 2006.

[5] J. M. Lopez-Higuera, L. Rodriguez Cobo, A. Quintela Incera, and A. Cobo, "Fiber Optic Sensors in Structural Health Monitoring," J. Light. Technol., vol. 29, no. 4, pp. 587-608, 2011.

[6] Li, Hong-Nan, Dong-Sheng Li, and Gang-Bing Song. "Recent applications of fiber optic sensors to health monitoring in civil engineering." Engineering structures 26.11, 1647-1657, 2004.

[7] Ye, X. W., Y. H. Su, and J. P. Han. "Structural health monitoring of civil infrastructure using optical fiber sensing technology: A comprehensive review." The Scientific World Journal 2014, 2014.

[8] Tan, Yisong, Jianhua Zhu, and Limin Ren. "A Two-Dimensional Wireless and Passive Sensor for Stress Monitoring." Sensors 19.1, 135, 2019.

[9] S. A. A. Jabir and N. K. Gupta, "Thick-film ceramic strain sensors for structural health monitoring," IEEE Trans. Instrum. Meas., vol. 60, no. 11, pp. 3669-3676, 2011.

[10] X. Jiang, Y. Tang, and Y. Lei, "Wireless Sensor Networks in Structural Health Monitoring Based on ZigBee Technology," 3rd Int. Conf. Anti-counterfeiting, Secur. Identif. Commun., pp. 449-452, 2009.

[11] Tan, Yisong, Jianhua Zhu, and Limin Ren. "A Two-Dimensional Wireless and Passive Sensor for Stress Monitoring." Sensors 19, no. 1, 135, 2019.

[12] Y. Ikemoto, S. Suzuki, H. Okamoto, H. Murakami, H. Asama, S. Morishita, T. Mishima, X. Lin, and H. Itoh, "Force sensor system for structural health monitoring using passive RFID tags," Sens. Rev., vol. 29, no. 2, pp. 127-136, 2009.

[13] W. S. T. Rowe, A. R. As-Saber, S. N. Azemi, and K. Ghorbani, "3D frequency selective surfaces with highly selective reponses,” 2015 Loughbrgh. Antennas Propag. Conf. LAPC 2015, pp. 3-6, 2015.

[14] S. N. Azemi, K. Ghorbani, and W. S. T. Rowe, "3D Frequency Selective Surface," Prog. Electromagn. Res. C, Vol. 29, 191-203, 2012 3D, vol. 29, no. May, pp. 191-203, 2012.

[15] S. A. Suhaimi, S. N. Azemi, and P. J. Soh, "Structural Health Monitoring System using 3D Frequency Selective Surface," IEEE Asia-Pacific Conf. Appl. Electromagn., pp. 145-149, 2016.

\section{BIOGRAPHIES OF AUTHORS}

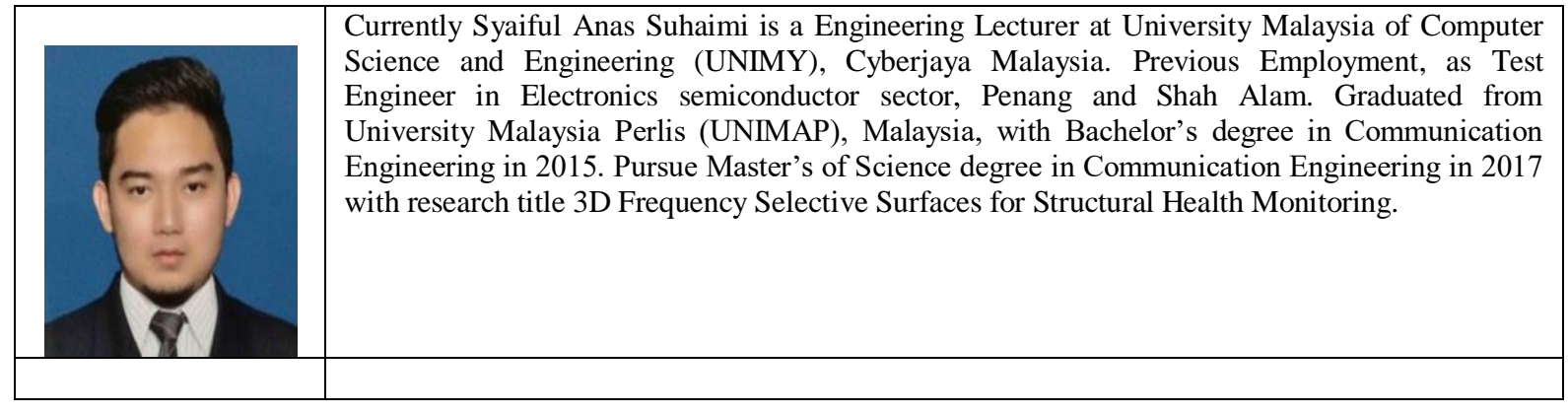

Highly sensitive frequency selective surface for structural health monitoring system (S. A. Suhaimi) 


\begin{tabular}{|c|c|}
\hline & $\begin{array}{l}\text { Dr. Saidatul Norlyana Azemi obtained her Ph.D in } 2014 \text { from Royal Melbourne Institute } \\
\text { Technology (RMIT) University, Melbourne Australia. She has received the Masters of Science } \\
\text { in Communication Engineering in } 2010 \text { from University Malaysia Perlis, Malaysia. Previously, } \\
\text { she obtained her first degree from University Malaysia Perlis, Malaysia, with Honors, } \\
\text { in Communication Engineering, graduating in 2007. In RMIT University Melbourne Australia, } \\
\text { Dr. Saidatul was a winner for Poster and Oral presentation two year in a row during Higher } \\
\text { Degree by Research Conference's day RMIT as well as School of Electrical and Computer } \\
\text { Engineering (SECE) Postgraduate Research Day. Dr. Saidatul was the recipient of the Best } \\
\text { Student Paper Award presented at the Malaysian Technical Universities Conference on } \\
\text { Engineering and Technology (MUCET 2017). She has published several impact factor journals, } \\
\text { national and international conference papers. Shee is currently a Senior Lecturer at the School of } \\
\text { Computer and Communication Engineering (SCCE), Universiti Malaysia Perlis (UniMAP). } \\
\text { Her research interest focus on 3-D and 2D Frequency Selective Surface, 3-D antenna structure, } \\
\text { antenna design and diversity, dielectric materials, wireless network, and RF \& microwave } \\
\text { design. }\end{array}$ \\
\hline & $\begin{array}{l}\text { Ping Jack Soh, C.Eng, was born in Sabah, Malaysia. He received the Bachelor and Master } \\
\text { degrees in Electrical Engineering (Telecommunication) from Universiti Teknologi Malaysia } \\
\text { (UTM) in } 2002 \text { and 2006, respectively, and the PhD degree in Electrical Engineering from KU } \\
\text { Leuven, Belgium in 2013. He is currently an Associate Professor at the School of Computer and } \\
\text { Communication Engineering (SCCE), Universiti Malaysia Perlis (UniMAP). He researches and } \\
\text { publishes actively in his areas of interest: wearable antennas, arrays, metasurfaces and systems; } \\
\text { on-body communication; electromagnetic safety and absorption; and wireless and radar } \\
\text { techniques for healthcare applications. Dr. Soh was the recipient of the IEEE Antennas and } \\
\text { Propagation Society (AP-S) Doctoral Research Award in 2012, the IEEE Microwave Theory and } \\
\text { Techniques Society (MTT-S) Graduate Fellowship for Medical Applications in } 2013 \text { and the } \\
\text { International Union of Radio Science (URSI) Young Scientist Award in 2015. He was also the } \\
\text { Second Place Winner of the IEEE Presidents' Change the World Competition and IEEE MTT-S } \\
\text { Video Competition, both in 2013. He is a Chartered Engineer registered with the UK } \\
\text { Engineering Council; a Senior Member of the IEEE, a Member of the IET, ACES and URSI; and } \\
\text { a Graduate Member of the BEM and the IEM. He also serves in the IEEE MTT-S EduComm, } \\
\text { and the IEEE MTT-S M\&S Committee. }\end{array}$ \\
\hline & $\begin{array}{l}\text { Mohd Rashidi Bin Che Beson (C.B.M. Rashidi) received his Bachelor of Engineering (Honours) } \\
\text { in Communication Engineering and MSc. Degree in Communication Engineering from } \\
\text { Universiti Malaysia Perlis (UniMAP) Malaysia in } 2007 \text { and } 2011 \text { respectively. He received his } \\
\text { PhD in Communication Engineering in } 2014 \text { also from Universiti Malaysia Perlis (UniMAP) } \\
\text { Malaysia. He used to be an RND Electronic Engineer at Motorola Solution under Energy Group } \\
\text { Design, Penang in } 2007 \text { until 2009. He is currently working as Deputy Dean at Research } \\
\text { Management and Innovation Centre (RMIC), UniMAP, senior lecturer in School of Computer } \\
\text { and Communication Engineering and a principle coordinator/researcher at the Advanced } \\
\text { Communication Engineering, Centre of Excellence - School of Computer and Communication } \\
\text { Engineering (ACE CoE - SCCE). His research interest is in Optical CDMA technology, } \\
\text { Radio over Fiber (RoF) and Fiber sensor technologies. He is an IEEE member (No. 93040632), } \\
\text { IET member (1100458911) and he was a committee of IEEE Photonics Society Malaysia } \\
\text { Chapter since 2015-2016. }\end{array}$ \\
\hline$=$ & $\begin{array}{l}\text { Azremi Abdullah Al-Hadi was born on August 26, in Michigan, United States of America. } \\
\text { He received the Master of Science degree in communication engineering from Birmingham } \\
\text { University, United Kingdom in } 2004 \text { and the Doctor of Science in Technology degree from } \\
\text { Aalto University, Finland in } 2013 \text {. His current research interests include design and performance } \\
\text { evaluation of multi-element antennas, mobile terminal antennas and their user interactions, } \\
\text { and wireless propagation. He is currently working as an Associate Professor and holds position } \\
\text { as Dean of the School of Computer and Communication Engineering, Universiti Malaysia Perlis } \\
\text { (UniMAP). He has been with the school since 2002. He is active in volunteer work with IEEE } \\
\text { Malaysia Section, acting as the Senior Member of IEEE, executive committee in the IEEE } \\
\text { Antenna Propagation / Microwave Theory techniques / Electromagnetic Compatibility } \\
\text { (AP/MTT/EMC) Malaysia Chapter and Counselor for the IEEE UniMAP Student Branch. He is } \\
\text { the Chartered Engineer of the Institution of Engineering and Technology (IET), UK and the } \\
\text { member of the Board of Engineers Malaysia (BEM), Malaysia. Dr. Azremi was the recipient of } \\
\text { the Best Student Paper Award presented at the 5th Loughborough Antennas and Propagation } \\
\text { Conference (LAPC 2009) and the CST University Publication Award in 2011. }\end{array}$ \\
\hline
\end{tabular}

